\title{
ВЛИЯНИЕ ПЕРЕДОВЫХ ТЕХНОЛОГИЙ НА ОБЪЕМ ДОБЫЧИ НЕФТИ
}

\begin{abstract}
АНнотАЦия. В статье исследуются показатели, влияющие на объем добычи нефти, а также характеризующие уровень инновационного развития отрасли: число используемых передовых технологий, инвестиции в основной капитал, основные производственные фонды, коммерческий обмен технологиями с зарубежными странами, среднесписочная численность работников нефтедобывающей промышленности. Для определения наиболее важных показателей использована линейная модель множественной регрессии, построена матрица парных коэффициентов. Последовательно, исключая переменные, определены факторы, которые оказывают наибольшее влияние на объем добычи. В результате исследования выявлено, что изменения объемов добычи нефти объясняется изменчивостью использования передовых технологий. кЛЮчЕВЫЕ СЛОВА. Объем добычи нефти; передовые технологии; основные фонды; инвестиции в основной капитал; среднесписочная численность работников. ИНФОРМАЦИЯ О СТАТЬЕ. Дата поступления 31 марта 2017 г.; дата принятия к печати 15 апреля 2017 г.; дата онлайн-размещения 20 июня 2017 г.
\end{abstract}

O. S. Kozlova

Baikal State University, Irkutsk, Russian Federation

\section{INFLUENCE OF ADVANCED TECHNOLOGIES ON OIL PRODUCTION VOLUMES}

\begin{abstract}
The article examines the indicators that influence oil production volumes, as well as those that characterize the level of innovative development of the industry: the number of advanced technologies used, investments in the fixed assets, basic production assets, commercial exchange of technology with foreign countries, and the average number of workers in the oil industry. To determine the most important indicators, the article uses a linear model of multiple regression and builds a matrix of paired coefficients. Consistently, it identifies, excluding the variables, the factors that have the greatest impact on the extend of production are. As a result of the study, it reveals that changes in oil production volumes are due to the variability in the use of advanced technologies.

KEYWORDS. Volume of oil production; advanced technologies; fixed assets; investments in fixed assets; average number of employees.

ARTICLE INFO. Received March 31, 2017; accepted April 15, 2017; available online June 20, 2017.
\end{abstract}

Используя линейную модель множественной регрессии [1-4] рассмотрены показатели, оказывающие влияние на изменение объемов добычи нефти и характеризующие уровень инновационного развития отрасли [5-12]. Рассмотрены такие показатели как число используемых передовых технологий, коммерческий обмен технологиями с зарубежными странами, инвестиции в основной капитал, среднесписочная численность работников нефтедобывающей промышленности, основные производственные фонды.

Проанализированы данные за период с 1996 по 2015 г.

Количество основных переменных 6 - одна зависимая и 5 независимых:

1. Зависимая: $y$ - объем добычи нефти млн т.

(c) О. С. Козлова, 2017

\section{Baikal Research Journal}


2. Независимые:

- $x_{1}$ - число используемых передовых технологий, ед.;

$-x_{2}-$ коммерческий обмен технологиями с зарубежными странами, число соглашений;

$-x_{3}$ - инвестиции в основной капитал, млн р.;

- $x_{4}$ - среднесписочная численность работников нефтедобывающей промышленности, тыс. чел.;

$-x_{5}-$ основные производственные фонды, млн $\mathrm{p}$.

Количество наблюдений равно -20 .

Исходные данные представлены в табл. 1 .

Исходные данные для расчета

\begin{tabular}{|c|c|c|c|c|c|}
\hline $\begin{array}{c}\text { Объем } \\
\text { добычи, } \\
y\end{array}$ & \begin{tabular}{|c|} 
Число исполь- \\
зуемых пере- \\
довых техноло- \\
гий, $x_{1}$ \\
\end{tabular} & $\begin{array}{c}\text { Коммерческий } \\
\text { обмен технологи- } \\
\text { ями с зарубежны- } \\
\text { ми странами, } x_{2} \\
\end{array}$ & $\begin{array}{c}\text { Инвестиции } \\
\text { в основной } \\
\text { капитал, } x_{3}\end{array}$ & $\begin{array}{c}\text { Среднесписочная } \\
\text { численность работни- } \\
\text { ков нефтедобывающей } \\
\text { промышленности, } x_{4} \\
\end{array}$ & $\begin{array}{l}\text { Основные } \\
\text { фонды, } x_{5}\end{array}$ \\
\hline 303 & 413 & 6 & 22500,0 & 246,2 & 540337 \\
\hline 307 & 641 & 12 & 28765,0 & 263,7 & 520451 \\
\hline 304 & 852 & 24 & 29537,0 & 289,2 & 508785 \\
\hline 305 & 1462 & 60 & 58686,0 & 261,3 & 504328 \\
\hline 323 & 1518 & 62 & 135159,0 & 267,5 & 589316 \\
\hline 348 & 1940 & 54 & 190404,0 & 347,1 & 727972 \\
\hline 380 & 1706 & 54 & 186673,0 & 331,5 & 1334734 \\
\hline 421 & 2436 & 49 & 211793,0 & 320,8 & 1461207 \\
\hline 459 & 2254 & 66 & 190353,0 & 293,3 & 1706012 \\
\hline 470 & 3459 & 85 & 263172,6 & 263,3 & 1998553 \\
\hline 481 & $\begin{array}{ll}3 & 181 \\
\end{array}$ & 69 & 396463,3 & 238,9 & 2411843 \\
\hline 491 & 3934 & 69 & 505278,6 & 163,5 & 2924300 \\
\hline 489 & 4853 & 81 & 625506,2 & 151,6 & 3601172 \\
\hline 494 & 5697 & 49 & 616809,3 & 146,8 & 4657283 \\
\hline 505 & $\begin{array}{lll}6 & 032 \\
\end{array}$ & 39 & 639379,0 & 146,0 & 5343443 \\
\hline 511 & 6289 & 58 & 749501,6 & 143,3 & 6101602 \\
\hline 518 & 7475 & 68 & 871305,4 & 143,2 & 6980790 \\
\hline 523 & 7080 & 123 & 986743,8 & 135,3 & 8013675 \\
\hline 526 & 6448 & 70 & 1130285,8 & 139,4 & 9344223 \\
\hline 534 & 6619 & 67 & 1304658,3 & 141,8 & 11325194 \\
\hline
\end{tabular}

1. Оценка взаимосвязей. Матрица парных коэффициентов корреляции представлена в табл. 2.

Таблица 2

Матрица парных коэффициентов корреляции

\begin{tabular}{|r|r|r|r|r|r|r|}
\hline & \multicolumn{1}{|c|}{$y$} & \multicolumn{1}{|c|}{$x_{1}$} & \multicolumn{1}{c|}{$x_{2}$} & \multicolumn{1}{c|}{$x_{3}$} & \multicolumn{1}{|c|}{$x_{4}$} & \multicolumn{1}{|c|}{$x_{5}$} \\
\hline$y$ & 1 & & & & & \\
\hline$x_{1}$ & $\mathbf{0 , 9 1 1 3 0 3}$ & 1 & & & & \\
\hline$x_{2}$ & 0,632056 & 0,581530 & 1 & & & \\
\hline$x_{3}$ & $\mathbf{0 , 8 5 5 8 3 7}$ & 0,937620 & 0,544056 & 1 & & \\
\hline$x_{4}$ & $-0,746390$ & $-0,862120$ & $-0,363400$ & $-0,832530$ & 1 & \\
\hline$x_{5}$ & $\mathbf{0 , 8 1 0 ~ 0 8 6}$ & 0,910306 & 0,472842 & 0,986490 & $-0,808750$ & 1 \\
\hline
\end{tabular}

Из табл. 2 видно, что с зависимой переменной тесно связаны переменные: число используемых передовых технологий, инвестиции в основной капитал, основные производственные фонды. С остальными независимыми переменными объем добычи нефти также связан, но слабее.

\section{Baikal Research Journal}


2. Первая модель. Используем все независимые переменные.

$$
y=a+b_{1} x_{1}+b_{2} x_{2}+\ldots+b_{5} x_{5} .
$$

Результаты расчетов представлены в табл. 3-5.

\section{Регрессионная статистика}

\begin{tabular}{|l|r|}
\hline \multicolumn{1}{|c|}{ Показатель } & Значение \\
\hline Множественный $R$ & 0,925 \\
\hline$R^{2}$ & 0,857 \\
\hline Нормированный $R^{2}$ & 0,806 \\
\hline Стандартная ошибка & 38,85 \\
\hline Наблюдения & 20 \\
\hline
\end{tabular}

Таблица 3

Таблица 4

Дисперсионный анализ

\begin{tabular}{|l|r|r|r|r|r|r|}
\hline \multicolumn{1}{|c|}{ Показатель } & \multicolumn{1}{|c|}{$\mathrm{Df}$} & \multicolumn{1}{c|}{ SS } & \multicolumn{1}{|c|}{$M S$} & \multicolumn{2}{|c|}{ Значимость $F$} \\
\hline Регрессия & 5 & 126908,2 & 25381,6 & 16,8 & 1,7 & - \\
\hline Остаток & 14 & 21132,5 & 1509,4 & - & - & - \\
\hline Всего & 19 & 148040,8 & - & - & - & - \\
\hline
\end{tabular}

Таблица 5

Анализ параметров модели

\begin{tabular}{|c|r|r|r|r|r|r|}
\hline Переменные & Коэффициенты & $\begin{array}{c}\text { Стандартная } \\
\text { ошибка }\end{array}$ & $t$-статистика & $\begin{array}{l}\text { P-значение } \\
\text { Нижние } \\
95 \%\end{array}$ & $\begin{array}{c}\text { Верхние } \\
\mathbf{9} \%\end{array}$ \\
\hline$Y$-пересечение & 253,1 & 78,59 & 3,220 & 0,00 & 84,54 & 421,69 \\
\hline$x_{1}$ & 0,031 & $\mathbf{0 , 0 1}$ & 2,492 & 0,02 & $\mathbf{0 , 0 0}$ & $\mathbf{0 , 0 5}$ \\
\hline$x_{2}$ & 0,239 & 0,50 & $0,468(\mathrm{~min})$ & 0,64 & $-0,85$ & 1,33 \\
\hline$x_{3}$ & 0,000 & $\mathbf{0 , 0 0}$ & 0,940 & 0,36 & $-\mathbf{0 , 0 0}$ & $\mathbf{0 , 0 0}$ \\
\hline$x_{4}$ & 0,147 & $\mathbf{0 , 2 5}$ & 0,576 & 0,57 & $-\mathbf{0 , 4 0}$ & $\mathbf{0 , 6 9}$ \\
\hline$x_{5}$ & $-1,864$ & 1,93 & $-0,965$ & 0,35 & $-6,00$ & 2,27 \\
\hline
\end{tabular}

Полученная на первой интерации модель имеет вид:

$$
\begin{aligned}
& y=253,1+0,031 x_{1}+0,239 x_{2}+0,000 x_{3}+0,147 x_{4}-1,864 x_{1} \\
& \begin{array}{lllll}
\left(t_{a}=3,22\right) & (2,49) \quad(0,46) & (0,94) & (0,57) & (-0,96)
\end{array}
\end{aligned}
$$

Критическая точка $t_{\kappa p}=t(a, n-k)$ при уровне значимости $a=1-0,95=0,05$, которая зависит от числа степеней свободы, равного $(n-k)=20-6=14$, где $n=20$ число наблюдений, $k=5+1$ - число оцененных параметров модели (5 независимых и 1 зависимая переменная), $t_{\kappa p}=2,14$ [1-4].

3. Последовательно исключая переменные с наименьшей $t$-статистикой, по модулю не превышающей $t_{\kappa p}$ (т. е. наименее значимые факторы), определим какие факторы оказывают наибольшее влияние на объем добычи нефти.

Первый фактор, исключаемый из модели - это $x_{2}(t$-статистика $=0,468)$ (табл. 6).

Таблица 6

\section{Анализ паралетров модели}

\begin{tabular}{|c|r|r|r|r|r|r|}
\hline Переменные & Коэффициенты & $\begin{array}{c}\text { Стандартная } \\
\text { ошибка }\end{array}$ & $t$-статистика & $P$-значение & $\begin{array}{c}\text { Нижние } \\
95 \%\end{array}$ & $\begin{array}{c}\text { Верхние } \\
95 \%\end{array}$ \\
\hline$Y$-пересечение & 246,270 & 75,190 & 3,275 & 0,005 & 86,007 & 406,537 \\
\hline$x_{1}$ & 0,033 & 0,011 & 2,839 & 0,012 & 0,008 & 0,058 \\
\hline$x_{3}$ & 0,000 & 0,000 & 1,328 & 0,203 & $-0,000$ & 0,000 \\
\hline$x_{4}$ & 0,194 & 0,229 & $0,846(\mathrm{~min})$ & 0,410 & $-0,294$ & 0,683 \\
\hline$x_{5}$ & $-2,287$ & 1,662 & $-1,376$ & 0,188 & $-5,830$ & 1,254 \\
\hline
\end{tabular}

\section{Baikal Research Journal}


$t_{\kappa p}=2,13 ; 5$ оцененных параметров. При этом значение $F$-статистики выросло $(22,1)$, значение коэффициента детерминации осталось на прежнем уровне $R^{2}=0,855$.

Второй фактор, исключаемый из модели - это $x_{4}(t$-статистика $=0,846)$ (табл. 7).

Таблица 7

Анализ параметров модели

\begin{tabular}{|c|r|r|r|r|r|r|}
\hline Переменные & Коэффициенты & $\begin{array}{c}\text { Стандартная } \\
\text { ошибка }\end{array}$ & $t$-статистика & $P$-значение & $\begin{array}{c}\text { Нижние } \\
95 \%\end{array}$ & $\begin{array}{c}\text { Верхние } \\
95 \%\end{array}$ \\
\hline$Y$-пересечение & 308,171 & 17,428 & 17,681 & 6,336 & 271,224 & 345,118 \\
\hline$x_{1}$ & 0,029 & 0,010 & 2,755 & 0,014 & 0,006 & 0,052 \\
\hline$x_{3}$ & 0,000 & 0,000 & $1,273(\mathrm{~min})$ & 0,221 & $-0,000$ & 0,000 \\
\hline$x_{5}$ & $-2,240$ & 1,646 & $-1,361$ & 0,192 & $-5,731$ & 1,249 \\
\hline
\end{tabular}

$t_{\kappa p}=2,12 ; 4$ оцененных параметра. При этом значение $F$-статистики выросло $(29,77)$, значение коэффициента детерминации уменьшилось $R^{2}=0,848$.

Третий фактор, исключаемый из модели - это $x_{3}(t$-статистика $=-1,273)$ (табл. 8).

Таблица 8

Анализ параметров модели

\begin{tabular}{|c|r|r|r|r|r|r|}
\hline Переменные & Коэффициенты & $\begin{array}{c}\text { Стандартная } \\
\text { ошибка }\end{array}$ & $t$-статистика & $\begin{array}{r}P \text {-значение } \\
\text { Нижние } \\
95 \%\end{array}$ & $\begin{array}{c}\text { Верхние } \\
95 \%\end{array}$ \\
\hline$Y$-пересечение & 306,027 & 17,661 & 17,327 & 3,076 & 268,764 & 343,289 \\
\hline$x_{1}$ & 0,037 & 0,008 & 4,234 & 0,000 & 0,018 & 0,056 \\
\hline$x_{5}$ & $-3,040$ & 6,410 & $-0,474(\min )$ & 0,641 & $-1,656$ & 1,048 \\
\hline
\end{tabular}

$t_{\kappa p}=2,11 ; 3$ оцененных параметра. При этом значение $F$-статистики выросло $(42,30)$, значение коэффициента детерминации уменьшилось $R^{2}=0,832$.

Четвертый фактор, исключаемый из модели - это $x_{5}(t$-статистика $=-0,474)$ (табл. 9).

Таблица 9

Анализ параметров модели

\begin{tabular}{|c|r|r|r|r|r|r|}
\hline Переменные & Коэффициенты & $\begin{array}{c}\text { Стандартная } \\
\text { ошибка }\end{array}$ & & & $\begin{array}{c}\text { Нижатистика } \\
95 \%\end{array}$ & $\begin{array}{c}\text { Верхние } \\
95 \%\end{array}$ \\
\hline$Y$-пересечение & 309,500 & 15,722 & 19,685 & 1,266 & 276,468 & 342,531 \\
\hline$x_{1}$ & 0,033 & 0,003 & 9,390 & 0,000 & 0,026 & 0,041 \\
\hline
\end{tabular}

$t_{\kappa p}=2,1 ; 2$ оцененных параметра. При этом значение $F$-статистики выросло $(88,17)$, значение коэффициента детерминации уменьшилось $R^{2}=0,830$.

Коэффициент $x_{1}$ статистически значим с вероятностью $95 \%$. Полученная модель по критерию Фишера является пригодной $\left(F=88,17, R^{2}=0,830\right)$ [1-4]. Уравнение модели имеет следующий вид:

$$
\begin{aligned}
& y=309,5+0,033 x_{1} \\
& \left(t_{a}=19,68\right) \quad(9,39)
\end{aligned}
$$

Интерпретация коэффициентов регрессии:

$-a=309,5$ млн т интерпретации не подлежит, так как не значим;

$-b_{1}=0,033$ означает, что если объем добычи нефти увеличится на 1 млн т, то число используемых передовых технологий увеличится на 0,033 единицы, можно сказать, что внедрение передовых технологий способствует увеличению объемов добычи нефти. $R^{2}=0,830$, показывает, что вариация объемов добычи нефти на 83,0 \% объясняется изменчивостью использования передовых технологий, при этом оставшиеся 17 \% приходятся на неучтенные в модели факторы.

\section{Baikal Research Journal}


Вывод. Основным фактором, влияющим на изменение объемов добычи нефти, является использование передовых технологий.

\section{Список использованной литературы}

1. Абдуллин Р. 3. Эконометрика в MS EXSEL : практикум / Р. З. Абдуллин, В. Р. Абдуллин. - Иркутск : Изд-во Байкал. гос. ун-та, 2016. - 134 с.

2. Никифорова И. А. Линейная алгебра : курс лекций / И. А. Никифорова, Н. П. Шерстянкина. - Иркутск : Изд-во БГУЭП, 2015. - 100 с.

3. Болданова Е. В. Экономико-математические методы и модели : учеб. пособие / Е. В. Болданова. - Иркутск : Изд-во БГУЭП, 2015. - 139 с.

4. Ежова Л. Н. Эконометрические методы и модели : учеб. пособие / Л. Н. Ежова, Р. 3. Абдуллин, В. Р. Абдуллин. - Иркутск : Изд-во БГУЭП, 2012. - 91 с.

5. Троицкая Л. И. Развитие, инновации, управление / Л. И. Троицкая, Е. В. Пьянова. - Иркутск : Изд-во БГУЭП, 2010. - 111 с.

6. Дунаев В. Ф. Экономика предприятий нефтяной и газовой промышленности / В. Ф. Дунаев, В. А. Шпаков. - 3-е изд., испр. и доп. - М. : ЦентрЛитНефтегаз, 2008. - 305 с.

7. Коржубаев А. Г. Нефтедобывающая промышленность России / А. Г. Коржубаев, Л. В. Эдер // Бурение и нефть. - 2011. - № 4. - С. 3-8.

8. Кузбожьев Э. Н. Экономика отрасли: конкуренция, конкурентоспособность и отраслевой потенциал / Э. Н. Кузбожьев, О. А. Сухорукова, Н. Е. Цуканова. - Курск : Кур. гос. техн. ун-т, 2006. -292 с.

9. Мастепанов А. М. Топливно энергетический комплекс России на рубеже веков: состояние, проблемы и перспективы развития : справ.-аналит. сб. : в 2 т. / А. М. Мастепанов. - Изд. 4-е, перераб. и доп. - М. : Энергия, 2009. - Т. 1. - 480 с. ; Т. 2. - 472 с.

10. Колядин Н. П. К проблеме построения матричной модели «инвестиции - инновации - институты» / Н. П. Колядин, А. Н. Неверов // Вестник Саратовского государственного социально-экономического университета. - 2012. - № 1 (40). - С. 29-33.

11. Бурый О. В. Энергоэкономическое прогнозирование развития региона / О. В. Бурый, В. Н. Лаженцев. - М. : Наука, 2008. - 365 с.

12. Добряков И. С. Основные направления и методы организационно экономических изменений на предприятиях нефтегазовой отрасли / И. С. Добряков // Вестник Мурманского государственного технического университета. - 2010. - Т. 13, № 1. - С. 192-198.

\section{References}

1. Abdullin R. Z., Abdullin V. R. Ekonometrika v MS EXSEL. Praktikum [Econometrics in MS EXSEL. Practical Course]. Irkutsk, Baikal State University Publ., 2016. 134 p.

2. Nikiforova I. A., Sherstyankina N. P. Lineinaya algebra : kurs lektsii [Linear Algebra: a Course of Lectures ]. Irkutsk, Baikal State University of Economics and Law Publ., 2015. $100 \mathrm{p}$.

3. Boldanova E. V. Ekonomiko-matematicheskie metody i modeli [Economic-mathematical methods and models]. Irkutsk, Baikal State University of Economics and Law Publ., 2015. 139 p.

4. Ezhova L. N., Abdullin R. Z., Abdullin V. R. Ekonometricheskie metody i modeli [Econometric methods and models]. Irkutsk, Baikal State University of Economics and Law Publ., 2012. 91 p.

5. Troitskaya L. I., Pyanova E. V. Razvitie, innovatsii, upravlenie [Development, innovations, management]. Irkutsk, Baikal State University of Economics and Law Publ., 2010. 111 p.

6. Dunayev V. F., Shpakov V. A. Ekonomika predpriyatii neftyanoi i gazovoi promyshlenno$s t i$ [Economy of enterprises of oil and gas industry]. $3^{\text {rd }}$ ed. Moscow, TsentrLitNeftegaz Publ., 2008. 305 p.

7. Korzhubayev A. G., Eder L. V. Oil industry of Russia. Burenie $i$ neft' $=$ Drilling and Oil, 2011, no. 4, pp. 3-8. (In Russian).

8. Korzhubayev E. N., Sukhorukova O. A., Tsukanova N. E. Ekonomika otrasli: konkurentsiya, konkurentosposobnost' $i$ otraslevoi potentsial [Economy of industry: competition, competitiveness and industry's potential]. Kursk State Technical University Publ., 2006. 292 p.

9. Mastepanov A. M. Toplivno-energeticheskii kompleks Rossii na rubezhe vekov: sostoyanie, problemy i perspektivy razvitiya [Fuel and Energy Complex of Russia at the Turn of the

\section{Baikal Research Journal}


Century: Status, Challenges and Opportunities]. $4^{\text {th }}$ ed. Moscow, Energiya Publ., 2009. Vol. 1. 480 p.; Vol. 2. 472 p.

10. Kolyadin N. P. Development of the «investment - innovation - institution» matrix model. Vestnik Saratovskogo gosudarstvennogo sotsial'no-ekonomicheskogo universiteta $=$ Bulletin of Saratov State Socio-Economic University, 20012, no. 1 (40), pp. 29-33. (In Russian).

11. Bury O. V., Lazhentsev V. N. Energoekonomicheskoe prognozirovanie razvitiya regiona [Energy-economic forecasting of the region's development]. Moscow, Nauka Publ., 2008. 365 p.

12. Dobryakov I. S. Basic conceptions and methods of organizational and economic modifications in oil and gas industry. Vestnik Murmanskogo gosudarstvennogo tekhnicheskogo universiteta $=$ Bulletin of Murmansk State Technical University, 2010, vol. 13, no. 1, pp. 192-198. (In Russian).

\section{Информация об авторе}

Козлова Ольга Сергеевна - аспирант, кафедра экономики и управления бизнеса, Байкальский государственный университет, 664003 г. Иркутск, ул. Ленина 11, e-mail: Okozlova81@mail.ru.

\section{Author}

Olga S. Kozlova - PhD Student, Department of Economics and Business Management, Baikal State University, 11 Lenin St., 664003, Irkutsk, Russian Federation; e-mail: Okozlova81@mail.ru.

\section{Библиографическое описание статьи}

Козлова О. С. Влияние передовых технологий на объемы добычи нефти / О. С. Козлова // Baikal Research Journal. — 2017. — T. 8, № 2. — DOI: 10.17150/2411-6262.2017.8(2).23.

\section{Reference to article}

Kozlova O. S. Influence of advanced technologies on oil production volumes. Baikal Research Journal, 2017, vol. 8, no. 2. DOI: 10.17150/2411-6262.2017.8(2).23. (In Russian).

\section{Baikal Research Journal}

